\title{
Effects and moderators of exercise on muscle strength, muscle function and aerobic fitness in patients with cancer: a meta-analysis of individual patient data
}

\author{
Maike G Sweegers, ${ }^{1,2}$ Teatske M Altenburg, ${ }^{3}$ Johannes Brug, ${ }_{1}^{4}$ Anne M May, ${ }_{1}^{5}$ \\ Jonna K van Vulpen, ${ }_{1}^{5}$ Neil K Aaronson, ${ }_{1}^{6}$ Gill Arbane, ${ }^{7}$ Martin Bohus, ${ }^{8,9}$ \\ Kerry S Courneya, ${ }^{10}$ Amanda J Daley, ${ }_{1}^{11}$ Daniel A Galvao, ${ }^{12}$ Rachel Garrod, ${ }^{13}$ \\ Kathleen A Griffith, ${ }^{14}$ Wim H Van Harten, ${ }^{6,15}$ Sandra C Hayes, ${ }^{16}$ \\ Fernando Herrero-Román, ${ }^{17}$ Marie J Kersten, ${ }^{18}$ Alejandro Lucia, ${ }^{19}$ Alex McConnachie, ${ }^{20}$ \\ Willem van Mechelen, ${ }_{1}^{3}$ Nanette Mutrie, ${ }^{21}$ Robert U Newton, ${ }^{12}$ Frans Nollet, ${ }^{22}$ \\ Karin Potthoff ${ }^{23,24}$ Martina E Schmidt, ${ }^{25}$ Kathryn H Schmitz, ${ }^{26}$ Karl Heinz Schulz, 27 \\ Gabe Sonke, ${ }^{28}$ Karen Steindorf, $^{25}$ Martijn M Stuiver, ${ }_{1}^{29}$ Dennis R Taaffe, ${ }_{1}^{12}$ \\ Lene Thorsen, ${ }^{30}$ Jos W Twisk, ${ }^{1}$ Miranda J Velthuis, ${ }^{31}$ Jennifer Wenzel, ${ }^{32}$ \\ Kerri M Winters-Stone ${ }_{13}^{33}$ Joachim Wiskemann, ${ }_{1}^{23,34}$ Mai J Chin A Paw, ${ }^{3}$ \\ Laurien M Buffart $1,2,12,35$
}

- Additional material is published online only. To view please visit the journal online (http://dx.doi.org/10.1136/ bjsports-2018-099191)

For numbered affiliations see end of article.

Correspondence to Laurien M Buffart, Department of Epidemiology and Biostatistics and Medical Oncology, VU University Medical Center, Amsterdam $1081 \mathrm{HV}$ The Netherlands: l.buffart@vumc.n

Accepted 6 August 2018 Published Online First 4 September 2018

Check for updates

(C) Author(s) (or their employer(s)) 2019. No commercial re-use. See rights and permissions. Published by BMJ.

To cite: Sweegers MG

Altenburg TM, Brug J,

et al. Br J Sports Med

2019:53:812

\section{ABSTRACT}

Objective To optimally target exercise interventions for patients with cancer, it is important to identify which patients benefit from which interventions.

Design We conducted an individual patient data meta-analysis to investigate demographic, clinical, intervention-related and exercise-related moderators of exercise intervention effects on physical fitness in patients with cancer.

Data sources We identified relevant studies via systematic searches in electronic databases (PubMed, Embase, PsycINFO and CINAHL).

Eligibility criteria We analysed data from 28 randomised controlled trials investigating the effects of exercise on upper body muscle strength (UBMS) and lower body muscle strength (LBMS), lower body muscle function (LBMF) and aerobic fitness in adult patients with cancer.

Results Exercise significantly improved UBMS ( $\beta=0.20$, 95\% Confidence Interval (CI) 0.14 to 0.26$)$, LBMS $(\beta=0.29,95 \% \mathrm{Cl} 0.23$ to 0.35$), \operatorname{LBMF}(\beta=0.16,95 \% \mathrm{Cl}$ 0.08 to 0.24 ) and aerobic fitness $(\beta=0.28,95 \% \mathrm{Cl} 0.23$ to 0.34 ), with larger effects for supervised interventions. Exercise effects on UBMS were larger during treatment, when supervised interventions included $\geq 3$ sessions per week, when resistance exercises were included and when session duration was $>60$ min. Exercise effects on LBMS were larger for patients who were living alone, for supervised interventions including resistance exercise and when session duration was $>60$ min. Exercise effects on aerobic fitness were larger for younger patients and when supervised interventions included aerobic exercise. Conclusion Exercise interventions during and following cancer treatment had small effects on UBMS, LBMS, LBMF and aerobic fitness. Demographic, interventionrelated and exercise-related characteristics including age, marital status, intervention timing, delivery mode and frequency and type and time of exercise sessions moderated the exercise effect on UBMS, LBMS and aerobic fitness.

\section{INTRODUCTION}

Patients with cancer often experience physical problems as a result of cancer or cancer treatment. ${ }^{1-3}$ Previous randomised controlled trials (RCTs) and meta-analyses have reported beneficial effects of exercise on physical fitness in patients with cancer. ${ }^{4-7}$ Physical fitness is defined by the body's ability to carry out daily tasks without excessive fatigue and is important for functional independence and quality of life (QoL). ${ }^{8}{ }^{9}$ Physical fitness includes, among others, upper body muscle strength (UBMS), lower body muscle strength (LBMS), lower body muscle function (LBMF) and aerobic fitness. ${ }^{10}$

A reduction in skeletal muscle mass during (neo-)adjuvant chemotherapy has been shown to be related to higher treatment toxicity and poorer survival. ${ }^{11-13}$ In the general population, poor LBMF is related to reduced functional independence and lower $\mathrm{QoL}^{14}{ }^{15}$ and is a significant predictor of mortality. ${ }^{16}$ Aerobic fitness was reported to be $25 \%$ lower in patients with breast cancer after chemotherapy than in healthy sedentary women. ${ }^{17}$ Functional independence is at risk when maximal aerobic fitness decreases below $15 \mathrm{~mL} / \mathrm{kg} / \mathrm{min},{ }^{18}$ and aerobic fitness is a well-established predictor of QoL ${ }^{19}$ and mortality ${ }^{40}$ in patients with cancer. Consequently, maintaining and improving strength, muscle function and aerobic fitness may be important during and following cancer treatment for functional independence and to improve QoL and potentially survival. ${ }^{89}$

Previous RCTs and meta-analyses have reported beneficial effects of exercise during and following 
treatment on muscle strength ${ }^{5-82122}$ and aerobic fitness ${ }^{4-8212324}$ in patients with different types of cancer. To effectively target and refine exercise interventions, it is important to identify which patients benefit from which exercise programmes. In addition, characteristics of the interventions may influence their effects on UBMS, LBMS, LBMF or aerobic fitness. ${ }^{25-27}$

Previously, we used data collected in the Predicting OptimaL cAncer RehabIlitation and Supportive care (POLARIS) study ${ }^{28}$ to conduct an individual patient data (IPD) meta-analysis to study demographic, clinical, intervention-related and exercise-related moderators of exercise intervention effects on self-reported QoL and self-reported physical function. ${ }^{29}$ Exercise effects on QoL and physical function were not significantly different between subgroups of patients with different demographic and clinical characteristics. However, moderators of the effect of exercise interventions may differ by outcome. Studies investigating moderators of the exercise intervention effects on physical fitness are scarce, and single RCTs are generally underpowered to investigate such moderator effects. The use of IPD from multiple RCTs allows testing of moderators with interaction tests in larger samples. ${ }^{30}$ Therefore, we aimed to identify demographic, clinical, intervention-related and exercise-related moderators of the exercise intervention effect on UBMS, LBMS, LBMF and aerobic fitness using IPD available in the POLARIS database. ${ }^{29}$

\section{METHODS}

Study and patient selection

We identified and obtained data from relevant studies as part of the POLARIS study. A description of the methods of study identification and selection has been published previously, and detailed information on the study inclusion can be found elsewhere. ${ }^{2829}$ Principal investigators of RCTs eligible to be included in the POLARIS study received a letter of invitation to join the consortium. After expressing interest, they signed a data sharing agreement. Anonymised data from study participants were shared in various formats, which were recoded, and checked for completeness and consistency with published results. The study protocol was registered in PROSPERO in February 2013 (CRD42013003805). ${ }^{28}$ In total, 34 RCTs evaluating the effects of exercise in patients with cancer were included in the POLARIS database. Of these studies, 28 reported UBMS, LBMS, LBMF and/or aerobic fitness and were included in the current IPD meta-analysis (figure 1). Due to a small sample of patients with metastatic disease, we excluded 50 patients with metastatic disease and another 15 patients for whom this information was missing .

\section{DATA EXTRACTION}

Study and patient characteristics (ie, country where the RCT was conducted, sample size, cancer type, mean age, sex and outcome measure), intervention characteristics (ie, timing, mode and duration of intervention delivery) and exercise characteristics (ie, frequency, intensity, type and time, often referred to as FITT-factors) were extracted by two independent researchers (MGS and LMB) and were based on documentation in published papers (online supplementary table 1 ).

\section{Risk of bias assessment}

We used the risk-of-bias assessment tool of the Cochrane Collaboration $^{31}$ to assess the risk of bias of the studies based on published papers. In our previous publication, we reported the risk of bias on random sequence generation, allocation concealment, incomplete outcome, incomplete reporting, adherence and

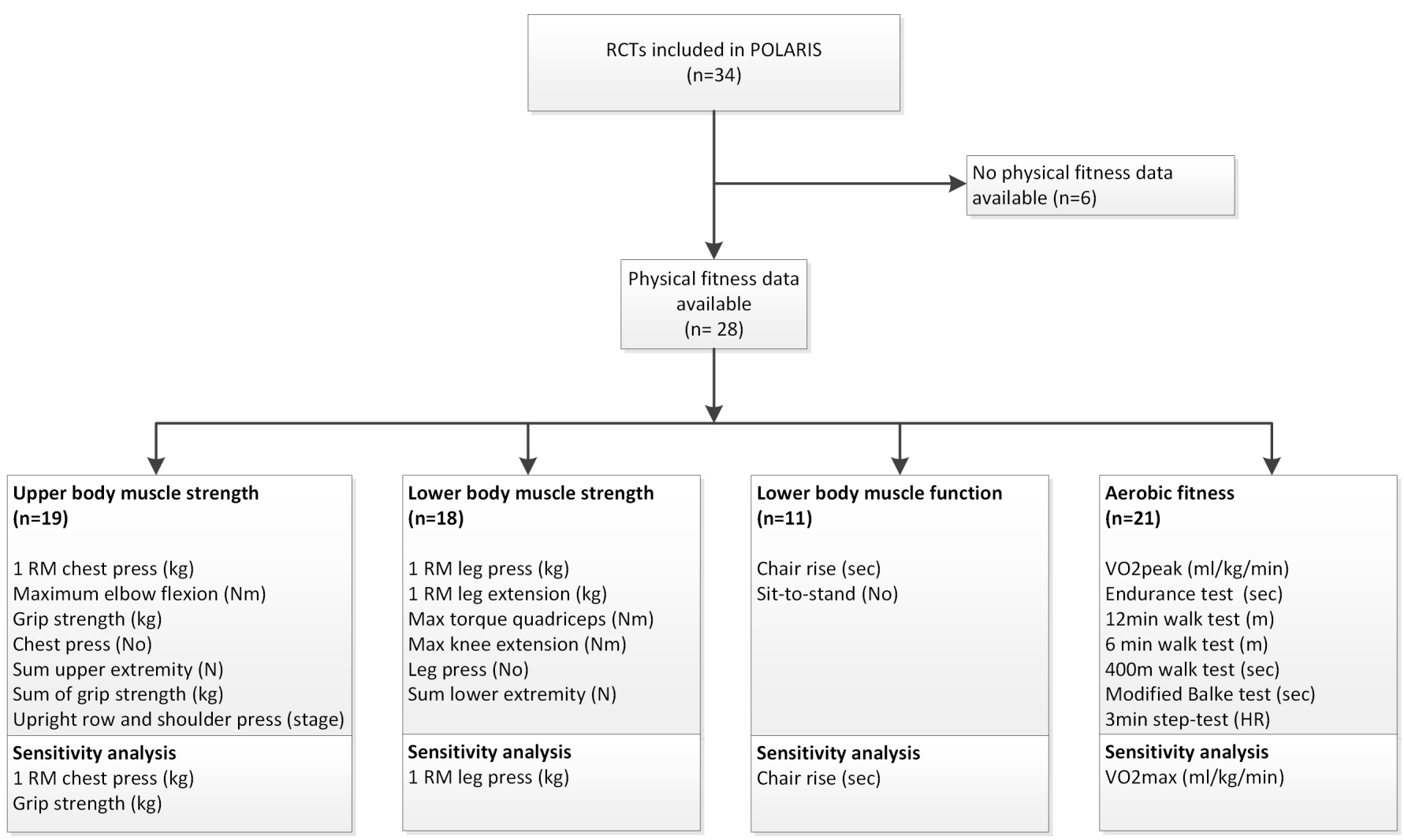

Figure 1 Flow of data inclusion. 1 RM, 1-repetition maximum; N, Newton; Nm, newton * meter; No, number of repetitions; RCT, randomised controlled trial; stage, based on number of repetitions and weight held; $\mathrm{VO}_{2}$ peak, peak oxygen consumption. 
contamination..$^{29}$ For the present study, we additionally assessed the risk of detection bias by judging blinding of outcome assessor. Two authors (MGS and LMB) independently judged this item as high risk of bias if the outcome assessor was not blinded or low risk of bias if the outcome assessor was blinded. If no information on blinding of outcome assessor was reported, the principal investigator of the study was contacted.

\section{Outcome measures}

The current IPD meta-analysis focused on UBMS, LBMS, LBMF and aerobic fitness after completion of the exercise intervention (figure 1). Studies included in the current meta-analysis measured UBMS with a one-repetition maximum (1RM) chest press $(\mathrm{kg}),{ }^{8}{ }^{32-40}$ maximum elbow flexion (Newton*metre $\left.(\mathrm{Nm})\right),{ }^{741}$ maximum grip strength $(\mathrm{kg}),{ }^{6} 23244243$ number of repetitions of chest press at 30\%-35\% of individual's body mass (No), ${ }^{44}$ sum of upper extremity isometric muscle strength measured using a handheld dynamometer (Newton $(\mathrm{N}))$, ${ }^{45}$ sum of best right and left grip strength $(\mathrm{kg})^{46}$ or an upright row and shoulder press exercise (stage based on number of repetitions and weight held). ${ }^{47}$ Four studies also reported grip strength in addition to the 1RM chest press or maximum elbow flexion and were included in the sensitivity analysis on grip strength. ${ }^{738-41}$ LBMS was measured using a $1 \mathrm{RM}$ leg press $(\mathrm{kg})^{932-40}$ or leg extension $(\mathrm{kg}),{ }^{8}$ maximum isometric quadriceps torque $(\mathrm{Nm}),{ }^{6} 234348-51$ maximum isometric knee extension $(\mathrm{Nm}),{ }^{7}$ number of repetitions of leg press at 100\%-110\% of individual's body mass $(\mathrm{No})^{44}$ or sum of lower body isometric muscle strength (hip abductors and flexors and knee flexors and extensors) measured using a handheld dynamometer $(\mathrm{N}) .{ }^{45}$ LBMF was measured using the chair rise (time in seconds to rise from the chair five times) $323335-4044$ or sit-to-stand test (number of times that participants raised to a full stand in $30 \mathrm{~s}$; No)..$^{7244143}$ Aerobic fitness was measured using a direct (maximal) or indirect (submaximal) cardiopulmonary exercise test (peak oxygen uptake, $\mathrm{VO}_{2}$ peak, in $\mathrm{mL} / \mathrm{kg} / \mathrm{min}$ ), ${ }^{6} 82324323342-444852-54$ during an endurance test (s) at $75 \%$ of maximal workload measured during a maximal short exercise capacity, ${ }^{74}$ as distance $(\mathrm{m})$ walked in $12^{55}$ or $6 \mathrm{~min},{ }^{45} 56$ during a $400 \mathrm{~m}$ walk test (s), ${ }^{32-37}$ a modified Balke test (time in seconds to reach $70 \%$ of age-predicted maximum heart rate (HR) during submaximal treadmill test ${ }^{46}$ or a 3 min step test (HR at test completion). ${ }^{47}$

To be able to pool the different measures per outcome, we recoded individual scores into $\mathrm{z}$-scores by calculating the mean score at baseline from all individuals per outcome measure and subtracting the mean score from the individual score. The result was divided by the mean SD per outcome measure at baseline. We used the z-scores for further analyses. If studies used more than one measure to investigate one of the outcomes, we used the best established measure based on the order provided in figure 1 and table 1 .

\section{Moderators of exercise on physical fitness}

Potential demographic moderators included baseline age, sex, marital status (dichotomized into unmarried or living alone vs married or living with partner) and education level (dichotomised

Table 1 Baseline upper body muscle strength (UBMS), lower body muscle strength (LBMS), lower body muscle function (LBMF) and aerobic fitness of patients in the exercise and control group

\begin{tabular}{|c|c|c|c|c|}
\hline \multirow[b]{2}{*}{ Baseline values } & \multirow[b]{2}{*}{$\mathbf{n}$} & \multirow{2}{*}{$\begin{array}{l}\text { Exercise }(n=1944) \\
\text { Mean (SD) }\end{array}$} & \multirow[b]{2}{*}{$\mathrm{n}$} & \multirow{2}{*}{$\begin{array}{l}\text { Control }(n=1571) \\
\text { Mean (SD) }\end{array}$} \\
\hline & & & & \\
\hline \multicolumn{5}{|l|}{ UBMS, mean (SD) } \\
\hline Max elbow flexion (Nm) & 150 & $30.5(12.1)$ & 72 & $28.7(13.0)$ \\
\hline Grip strength $(\mathrm{kg})$ & 378 & $35.3(10.7)$ & 290 & $36.4(9.8)$ \\
\hline Chest press (No) & 8 & $0.0(0.0)$ & 7 & $0.3(0.8)$ \\
\hline Row and shoulder press (stage) & 134 & $7.0(2.8)$ & 60 & $6.3(3.6)$ \\
\hline \multicolumn{5}{|l|}{ LBMS, mean (SD) } \\
\hline Leg press (1RM) & 498 & $104.0(42.9)$ & 430 & $99.6(44.3)$ \\
\hline Leg extension (1RM) & 160 & $54.1(26.1)$ & 82 & $56.4(27.7)$ \\
\hline Max quadriceps torque (Nm) & 268 & $105.5(35.0)$ & 309 & $103.9(36.4)$ \\
\hline \multicolumn{5}{|l|}{ LBMF, mean (SD) } \\
\hline Chair rise (s) & 339 & $12.2(3.2)$ & 273 & $12.0(3.1)$ \\
\hline Sit to stand (No) & 406 & $17.5(5.2)$ & 230 & $16.2(4.2)$ \\
\hline \multicolumn{5}{|l|}{ Aerobic fitness, mean (SD) } \\
\hline $\mathrm{VO}_{2}$ peak $(\mathrm{mL} / \mathrm{kg} / \mathrm{min})$ & 824 & $23.1(6.8)$ & 677 & $23.7(7.5)$ \\
\hline Endurance test (s) & 168 & $773.5(536.2)$ & 85 & $684.8(515.8)$ \\
\hline 12 min walk test $(\mathrm{m})$ & 99 & $997.4(211.0)$ & 100 & $975.4(234.6)$ \\
\hline 6 min walk test $(\mathrm{m})$ & 66 & $505.6(107.5)$ & 64 & $499.0(118.5)$ \\
\hline $400 \mathrm{~m}$ walk test (sec) & 190 & $273.7(55.2)$ & 128 & $271.3(46.6)$ \\
\hline Modified Balke test (sec) & 69 & $375.1(284.4)$ & 33 & $351.1(289.7)$ \\
\hline Step test (HR) & 117 & $122.5(16.1)$ & 46 & $115.2(14.7)$ \\
\hline
\end{tabular}

1RM, one-repetition maximum; $\mathrm{AE}$, aerobic exercise; $\mathrm{N}$, Newton; $\mathrm{Nm}$, newton ${ }^{*}$ metre; $\mathrm{No}$, number of repetitions; $\mathrm{RE}$, resistance exercise; t, time; $\mathrm{VO}_{2}$ peak, peak oxygen consumption. 
into low-medium, including elementary, primary or secondary school, lower or secondary vocational education vs high, including higher vocational, college or university education). ${ }^{29}$

Potential clinical moderators included body mass index (BMI), type of cancer (categorised into breast, male genitourinary, haematological, gastrointestinal, gynaecological, respiratory tract or other types) and type of treatment (surgery, chemotherapy, radiotherapy, hormone therapy or stem cell transplantation; all dichotomised into previous or current treatment vs no treatment). Since the majority of patients were women with breast cancer, we also investigated the moderator effect of type of cancer by dichotomising patients with breast cancer vs patients with other types of cancer.

Potential intervention-related moderators included timing of intervention delivery in relation to primary cancer treatment (categorised into during treatment and post-treatment, based on the Physical Activity and Cancer Control framework ${ }^{57}$ ), delivery mode of intervention (supervised when exercise sessions were conducted (partly) under supervision vs unsupervised when exercise sessions were performed at home) and intervention duration (categorised into $\leq 12$ weeks, $>12-24$ weeks and $>24$ weeks).

Potential exercise-related moderators (ie, FITT-factors) included exercise frequency (dichotomised into $<3$ vs $\geq 3$ sessions per week for supervised exercise and $<5 \mathrm{vs} \geq 5$ sessions per week for unsupervised exercise), exercise intensity (categorised into low, medium and high intensity based on the American College of Sports Medicine guidelines ${ }^{58}$ ), exercise type (categorised into aerobic exercise (AE); resistance exercise (RE); combined aerobic and resistance exercise (AE+RE); and combined resistance and impact loading exercise (RE+impact)) and session duration (categorised into $\leq 30 \mathrm{~min},>30-60 \mathrm{~min}$ or $>60 \mathrm{~min}$ per session). In addition, we calculated mean exercise volume (ie, frequency $\times$ session time) per week as a possible exercise-related moderator to investigate whether differences in effects as a result of exercise frequency are related to session duration. According to international physical activity guidelines, ${ }^{58}$ weekly exercise volume was dichotomised into $<150 \mathrm{~min} /$ week versus $\geq 150 \mathrm{~min} /$ week for both supervised and unsupervised exercise interventions.

\section{Statistical analyses}

We conducted one-step IPD meta-analyses without imputation of missing data to study the effects and moderators of exercise on UBMS, LBMS, LBMF and aerobic fitness. ${ }^{59}$ First, using z-values, we evaluated exercise effects by regressing the postintervention value of the outcome on the intervention, adjusted for the baseline value, using linear mixed model analyses. We used a two-level structure (1: patient; 2: study) and accounted for clustering of patients within studies by adding a random intercept on study level. In addition, we checked whether it was necessary to adjust the overall effect for age, sex, marital status, education level, BMI and cancer type, but because unadjusted effect sizes were not different from adjusted effects, unadjusted effect sizes were reported. Exercise intervention effects $(\beta)$ and $95 \%$ Confidence Intervals (CIs) were reported, and because z-values were used, the effects correspond to a Cohen's $d$ effect size.$^{60}$ Second, we conducted sensitivity analyses using raw data (ie, in their own unit of measurement) of the most frequently used outcome measures of UBMS, LBMS, LBMF and aerobic fitness (ie, chest press, grip strength, leg press, chair rise and directly measured $\mathrm{VO}_{2}$ peak) (figure 1).

All potential moderators were analysed in separate models, and for each potential moderator of exercise intervention effects, we examined significance of interaction terms with the likelihood ratio test. We reported $\chi^{2}$ values, $\mathrm{df}$ and $\mathrm{p}$ values. When a significant interaction was found, exercise intervention effects and $95 \% \mathrm{CI}$ were reported per stratum. If a significant interaction of a continuous variable was found, exercise intervention effects were reported for subgroups to facilitate interpretation of the results. In case a three-armed RCT had two exercise study arms with different exercise characteristics, we tested the difference between exercise characteristics using dummy variables, ${ }^{29}$ because interaction testing was not possible for that characteristic. In that case, we reported regression coefficients $\left(\beta_{\text {difference }}\right.$ ) and 95\% CI of the between-group difference in z-scores. If there was a significant between group difference, exercise intervention effects were reported per stratum. Effects of 0.2 were considered small, 0.5 as moderate and at or above 0.8 as large. ${ }^{6061}$

To reduce ecological bias (ie, bias that occurs when trials differ in other study level characteristics than the moderator of interest ${ }^{62}$ ), within-trial interaction was separated from between trial interaction and the individual values of the moderator were centred around the mean study value of that moderator. Due to the significant moderator effect of delivery mode on UBMS, LBMS and aerobic fitness, and because exercise characteristics differ between supervised and unsupervised exercise interventions, we investigated moderator effects of FITT-factors for supervised and unsupervised exercise interventions separately. Statistical analyses were performed using SPSS V.22.0 and R V.3.2.5. ${ }^{63}$

\section{RESULTS}

\section{Study characteristics}

The POLARIS database included 28 RCTs that evaluated the effect of exercise on UBMS, LBMS, LBMF and/or aerobic fitness (figure 2). In total, 3515 patients were included, of whom 1944 were randomised to the intervention group and 1571 to the control group. Nineteen RCTs evaluated the effect of exercise on UBMS, 18 on LBMS, 11 on LBMF and 21 on aerobic fitness (online supplementary table 1 ). The mean age of the participants was 54.9 (SD 11.7) years, $75 \%$ were female, $67 \%$ were diagnosed with breast cancer, $49 \%$ were highly educated and $76 \%$ were married or lived with a partner (table 2).

Regarding intervention characteristics, 10 RCTs investigated the effects of an exercise intervention during treatment, 14 following treatment, 3 during or following treatment and one pretreatment, during treatment or following treatment. Twenty-two RCTs investigated the effect of a supervised exercise intervention, five investigated an unsupervised exercise intervention and one investigated the effect of both an unsupervised and supervised exercise intervention arm. Eleven RCTs investigated an intervention duration of $\leq 12$ weeks, seven a duration of $>12-24$ weeks, eight a duration of $>24$ weeks and two reported median intervention duration only (online supplementary table 1).

Seventeen RCTs evaluating supervised exercise investigated a frequency of $<3$ times per week, and six RCTs evaluated a frequency of $\geq 3$ times per week. Three RCTs evaluating unsupervised exercise sessions investigated a frequency of $<5$ times per week, two RCTs $\geq 5$ times per week and one RCT did not report exercise frequency. For both supervised and unsupervised, 2 RCTs investigated the effect of low-moderate intensity exercise, 9 investigated moderate intensity, 16 investigated moderate-high intensity and 1 investigated high intensity exercise. Eight study arms investigated the effect of $\mathrm{AE}, 5$ the effect of RE, 14 the 

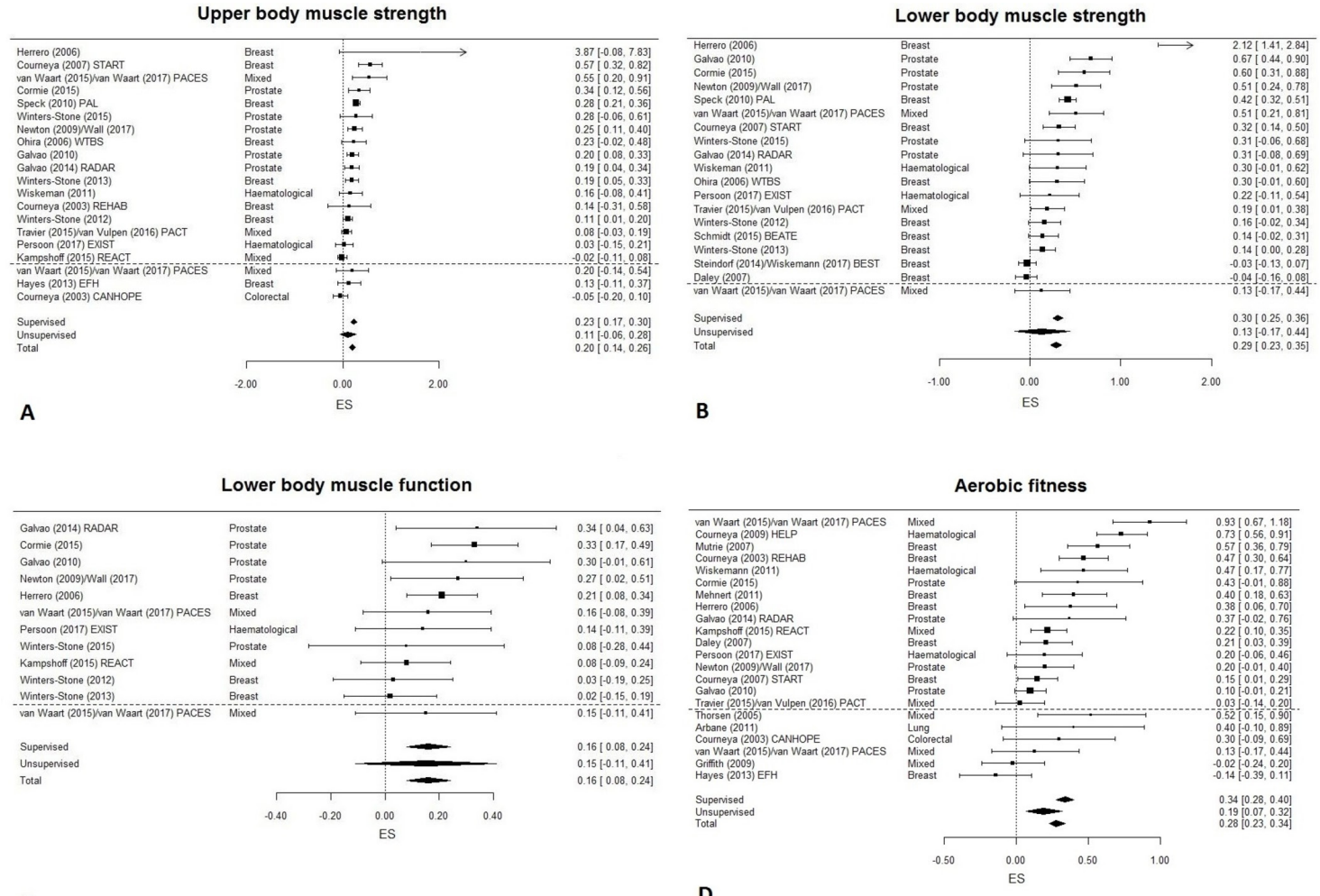

C

D

Figure 2 Forest plots of the effect sizes (ESs) of exercise intervention effects on upper body muscle strength (A), lower body muscle strength (B), lower body muscle function (C) and aerobic fitness (D). Data represent the regression coefficients ( $95 \% \mathrm{Cls}$ ) of the effects of exercise on physical fitness (in z-scores). Supervised interventions are presented above the dashed line and unsupervised interventions below. Pooled effects are presented at the bottom of the figures.

effect of $\mathrm{AE}+\mathrm{RE}$ and 4 the effect of RE+impact training. Eight RCTs investigated the effect of $\leq 30 \mathrm{~min}$ per exercise session, 16 of $>30-60 \mathrm{~min}, 3$ of $>60 \mathrm{~min}$ per session and 1 RCT did not report session duration (online supplementary table 1 ).

\section{Risk of bias assessment}

We previously reported the risk of bias of 26 of the 28 included RCTs. ${ }^{29}$ The risk of bias assessment of two RCTs ${ }^{36} 43$ could not be performed at that time because the papers were not yet published. Twenty-two RCTs were at low risk for selection bias, ${ }^{6-9} \quad 23 \quad 24 \quad 32-34 \quad 37-39 \quad 42 \quad 45-50 \quad 52 \quad 54-56$ allocation bias, ${ }^{6-8} 232432-3437-3942444547-5052-56$ and attrition bias due to the amount or handling of incomplete data, $^{6-9} 23243233$ 37-40 42 46-50 52-55 6421 RCTs were at low risk for bias due to selective outcome reporting, ${ }^{6-9} 232432-343738404245-5052555611$ RCTs reported high adherence to the intervention ${ }^{6233438404244454752-54}$ and 6 RCTs met the criteria of low risk of bias regarding limited contamination. ${ }^{82438-4042}$ Risk for detection bias was low in 13 RCTs due to adequate blinding of outcome assessors ${ }^{6923243438-40434447555664}$ and high in 15 RCTs $^{78323336374245464850-54}$ (online supplementary table 1). Because the lack of blinding could contribute to an overestimation of the overall effects, we investigated whether risk for detection bias was a moderator of the exercise effect on UBMS, LBMS, LBMF and aerobic fitness. There was a moderator effect of the risk for detection bias on UBMS $\left(\chi^{2}=6.86, \mathrm{df}=1, \mathrm{p}=0.01\right)$ and aerobic fitness $\left(\chi^{2}=14.04\right.$, $\mathrm{df}=1, \mathrm{p}<0.01)$ with larger effects for studies at high risk for detection bias.
Effects of exercise on physical fitness

Exercise interventions significantly improved UBMS $(\beta=0.20$, 95\% CI 0.14 to 0.26$)$, LBMS $(\beta=0.29,95 \%$ CI 0.23 to 0.35$)$, LBMF $(\beta=0.16,95 \%$ CI 0.08 to 0.24$)$ and aerobic fitness $(\beta=0.28$, 95\% CI 0.23 to 0.34 ; table 3$)$. Based on sensitivity analyses using a subset of the data with the original measurement unit, exercise significantly improved chest press (1RM) $(\beta=4.86,95 \%$ CI 3.65 to $6.07 \mathrm{~kg})$, leg press (1RM) $(\beta=16.56$, $95 \%$ CI 13.15 to $19.97 \mathrm{~kg})$, chair rise $(\beta=-0.60,95 \% \mathrm{CI}-0.91$ to $-0.28 \mathrm{~s}$ ) and $\mathrm{VO}_{2}$ peak $(\beta=1.80,95 \%$ CI 1.34 to $2.27 \mathrm{~mL} / \mathrm{kg} /$ min) compared with the control group. There were no significant between group differences for grip strength $(\beta=0.19,95 \%$ CI -0.39 to $0.76 \mathrm{~kg}$ ).

\section{Demographic and clinical moderators}

Intervention effects on LBMS were significantly larger $\left(\chi^{2}=5.12\right.$, $\mathrm{df}=1, \mathrm{p}=0.02)$ for patients who were unmarried or living alone ( $\beta=0.37,95 \%$ CI 0.23 to 0.51 ) than for those who were married or lived with their partner $(\beta=0.22,95 \%$ CI 0.14 to 0.30$)$. Intervention effects on aerobic fitness were significantly larger $\left(\chi^{2}=6.22, \mathrm{df}=1, \mathrm{p}=0.01\right)$ for younger patients. Effect sizes were 0.41 (95\% CI 0.31 to 0.52 ) for patients aged $<50$ years, 0.22 (95\% CI 0.15 to 0.29 ) for patients aged $50-70$ years and 0.23 (95\% CI 0.07 to 0.40 ) for patients aged $>70$ years. No other demographic or clinical characteristic significantly moderated the effects on UBMS, LBMS, LBMF or aerobic fitness (table 3).

\section{Intervention-related moderators}

Timing of intervention delivery significantly moderated the effect on UBMS $\left(\chi^{2}=4.17, \mathrm{df}=1, \mathrm{p}=0.04\right)$. There were larger 
Table 2 Demographic, clinical, intervention-related and exerciserelated characteristics of patients in the exercise and control group.

\begin{tabular}{|c|c|c|}
\hline & $\begin{array}{l}\text { Exercise } \\
(\mathrm{n}=1944)\end{array}$ & $\begin{array}{l}\text { Control } \\
(n=1571)\end{array}$ \\
\hline \multicolumn{3}{|l|}{ Demographic } \\
\hline Age, mean (SD) years & $54.9(11.9)$ & $55.0(11.6)$ \\
\hline \multicolumn{3}{|l|}{ Age categories (years), n (\%) } \\
\hline$<50$ & $648(33.3)$ & $501(31.9)$ \\
\hline $50-70$ & $1070(55.0)$ & $892(56.8)$ \\
\hline$\geq 70$ & $216(11.1)$ & $165(10.5)$ \\
\hline Unknown & $10(0.5)$ & $13(0.8)$ \\
\hline \multicolumn{3}{|l|}{ Sex, n (\%) } \\
\hline Men & $496(25.5)$ & $396(25.2)$ \\
\hline Women & $1448(74.5)$ & $1175(74.8)$ \\
\hline \multicolumn{3}{|l|}{ Married/living with partner, $\mathrm{n}(\%)$} \\
\hline Yes & $1150(59.2)$ & $891(56.7)$ \\
\hline No & $336(17.3)$ & $294(18.7)$ \\
\hline Unknown & $458(23.6)$ & $386(24.6)$ \\
\hline \multicolumn{3}{|l|}{ Education level, $n(\%)$} \\
\hline Low/middle & $864(44.4)$ & $657(41.8)$ \\
\hline High & $816(42.0)$ & $632(40.2)$ \\
\hline Unknown & $264(13.6)$ & $282(18.0)$ \\
\hline \multicolumn{3}{|l|}{ Clinical } \\
\hline $\mathrm{BMI}$, mean (SD) kg/m² & $27.08(5.0)$ & $27.42(5.3)$ \\
\hline \multicolumn{3}{|l|}{ BMI categories, $\mathrm{n}(\%)$} \\
\hline Underweight (BMI <18.5 kg/m²) & $13(0.7)$ & $18(1.2)$ \\
\hline Normal weight (BMI $18.5-<25 \mathrm{~kg} / \mathrm{m}^{2}$ ) & $697(35.9)$ & $513(32.7)$ \\
\hline Overweight (BMI 25-<30 kg/m²) & $676(34.8)$ & $549(35.0)$ \\
\hline Obese $\left(\mathrm{BMI} \geq 30 \mathrm{~kg} / \mathrm{m}^{2}\right)$ & $447(23.0)$ & $390(24.8)$ \\
\hline Unknown & $111(5.7)$ & $101(6.4)$ \\
\hline \multicolumn{3}{|l|}{ Cancer type, n (\%) } \\
\hline Breast & $1297(66.7)$ & $1056(67.2)$ \\
\hline Male genitourinary & $287(14.8)$ & $221(14.1)$ \\
\hline Haematological & $190(9.8)$ & $183(11.7)$ \\
\hline Gastrointestinal & $126(6.5)$ & $76(4.8)$ \\
\hline Gynaecological & $16(0.8)$ & $17(1.1)$ \\
\hline Respiratory track & $23(1.2)$ & $15(1.0)$ \\
\hline Other & $5(0.3)$ & $3(0.2)$ \\
\hline \multicolumn{3}{|l|}{ Surgery, $\mathrm{n}(\%)^{*}$} \\
\hline No & $265(14.3)$ & $219(14.8)$ \\
\hline Yes & $1458(78.8)$ & $1144(77.5)$ \\
\hline Unknown & $127(6.9)$ & $113(7.7)$ \\
\hline \multicolumn{3}{|l|}{ Chemotherapy, n (\%) } \\
\hline No & $498(25.6)$ & $412(26.2)$ \\
\hline Prior to intervention & $663(34.1)$ & $618(39.3)$ \\
\hline During intervention & $715(36.8)$ & $479(30.5)$ \\
\hline Unknown & $68(3.5)$ & $62(4.0)$ \\
\hline \multicolumn{3}{|l|}{ Radiotherapy, n (\%) } \\
\hline No & $850(43.7)$ & $616(39.2)$ \\
\hline Prior to intervention & $720(37.0)$ & $650(41.4)$ \\
\hline During intervention & $297(15.3)$ & $253(16.1)$ \\
\hline Unknown & $77(4.0)$ & $52(3.3)$ \\
\hline \multicolumn{3}{|l|}{ Hormone therapy } \\
\hline \multicolumn{3}{|l|}{ Breast cancer survivors $(n=2353), n(\%)$} \\
\hline No & $672(51.8)$ & $545(51.6)$ \\
\hline Yes & $365(28.1)$ & $261(24.7)$ \\
\hline Unknown & $260(20.1)$ & $250(23.7)$ \\
\hline \multicolumn{3}{|l|}{ Prostate cancer survivors $(\mathrm{n}=508), \mathrm{n}(\%)$} \\
\hline No & $0(0.0)$ & $0(0.0)$ \\
\hline
\end{tabular}

Table 2 Continued

\begin{tabular}{|c|c|c|}
\hline & $\begin{array}{l}\text { Exercise } \\
(n=1944)\end{array}$ & $\begin{array}{l}\text { Control } \\
(n=1571)\end{array}$ \\
\hline Prior to intervention & $50(17.4)$ & $50(22.6)$ \\
\hline During intervention & $190(66.2)$ & $125(56.6)$ \\
\hline Unknown & $47(16.4)$ & $46(20.8)$ \\
\hline \multicolumn{3}{|l|}{$\mathrm{SCT}, \mathrm{n}(\%) \dagger$} \\
\hline Allogeneic & $40(42.6)$ & $40(42.1)$ \\
\hline Autologous & $54(57.5)$ & $55(57.9)$ \\
\hline \multicolumn{3}{|l|}{ Intervention related $\ddagger$} \\
\hline \multicolumn{3}{|l|}{ Timing of intervention, $\mathrm{n}(\%)$} \\
\hline Pre-during-following treatment & $40(2.1)$ & \\
\hline During treatment & $1113(57.3)$ & \\
\hline Following treatment & $791(40.7)$ & \\
\hline \multicolumn{3}{|l|}{ Mode of intervention delivery, $\mathrm{n}(\%)$} \\
\hline (Partly) Supervised & $1527(78.6)$ & \\
\hline Unsupervised & $417(21.5)$ & \\
\hline \multicolumn{3}{|l|}{ Duration of intervention (weeks), $\mathrm{n}(\%)$} \\
\hline$\leq 12$ & $644(33.1)$ & \\
\hline$>12-24$ & $495(25.5)$ & \\
\hline$>24$ & $605(31.1)$ & \\
\hline Unknown§ & $200(10.3)$ & \\
\hline \multicolumn{3}{|l|}{ Exercise related } \\
\hline \multicolumn{3}{|l|}{ Exercise frequency, $n(\%)$} \\
\hline 2 times per week & $1250(64.3)$ & \\
\hline 3 times per week & $286(14.7)$ & \\
\hline 4 times per week & $192(9.9)$ & \\
\hline$\geq 5$ times per week & $193(9.9)$ & \\
\hline Unknown & $23(1.2)$ & \\
\hline \multicolumn{3}{|l|}{ Exercise intensity, $\mathrm{n}(\%)$} \\
\hline Low & $0(0.0)$ & \\
\hline Low-moderate & $167(8.6)$ & \\
\hline Moderate & $510(26.2)$ & \\
\hline Moderate-vigorous & $985(50.7)$ & \\
\hline Vigorous & $91(4.7)$ & \\
\hline Unknown & $191(9.8)$ & \\
\hline \multicolumn{3}{|l|}{ Exercise type, $n(\%)$} \\
\hline $\mathrm{AE}$ & $437(22.5)$ & \\
\hline RE & $385(19.8)$ & \\
\hline$A E+R E$ & $957(49.2)$ & \\
\hline $\mathrm{RE}+$ impact training & $165(8.5)$ & \\
\hline \multicolumn{3}{|l|}{ Exercise session duration (min), $\mathrm{n}(\%)$} \\
\hline$\leq 30$ & $544(28.0)$ & \\
\hline$>30-60$ & $1148(59.1)$ & \\
\hline$>60$ & $186(9.6)$ & \\
\hline Unknown & $66(3.4)$ & \\
\hline
\end{tabular}

*Proportion of survivors without $\mathrm{SCT}(\mathrm{n}=3326)$.

tProportion of survivors with SCT $(n=189)$.

¥Proportion of survivors from intervention groups $(n=1944)$.

$\S$ Intervention duration of individual patients unknown for three studies, but mean or median was reported.

$A E$, aerobic exercise; $B M I$, body mass index; $n$, number; RE, resistance exercise; $S C T$, stem cell transplantation.

effects when exercise interventions were delivered during treatment ( $\beta=0.26,95 \%$ CI 0.17 to 0.36 ) than following treatment $(\beta=0.13,95 \%$ CI 0.06 to 0.21$)$. In addition, the moderator effect of timing of the intervention delivery remained significant after adjusting for intervention delivery mode. The exercise intervention effects on UBMS, LBMS and aerobic fitness were significantly larger for supervised than for unsupervised 


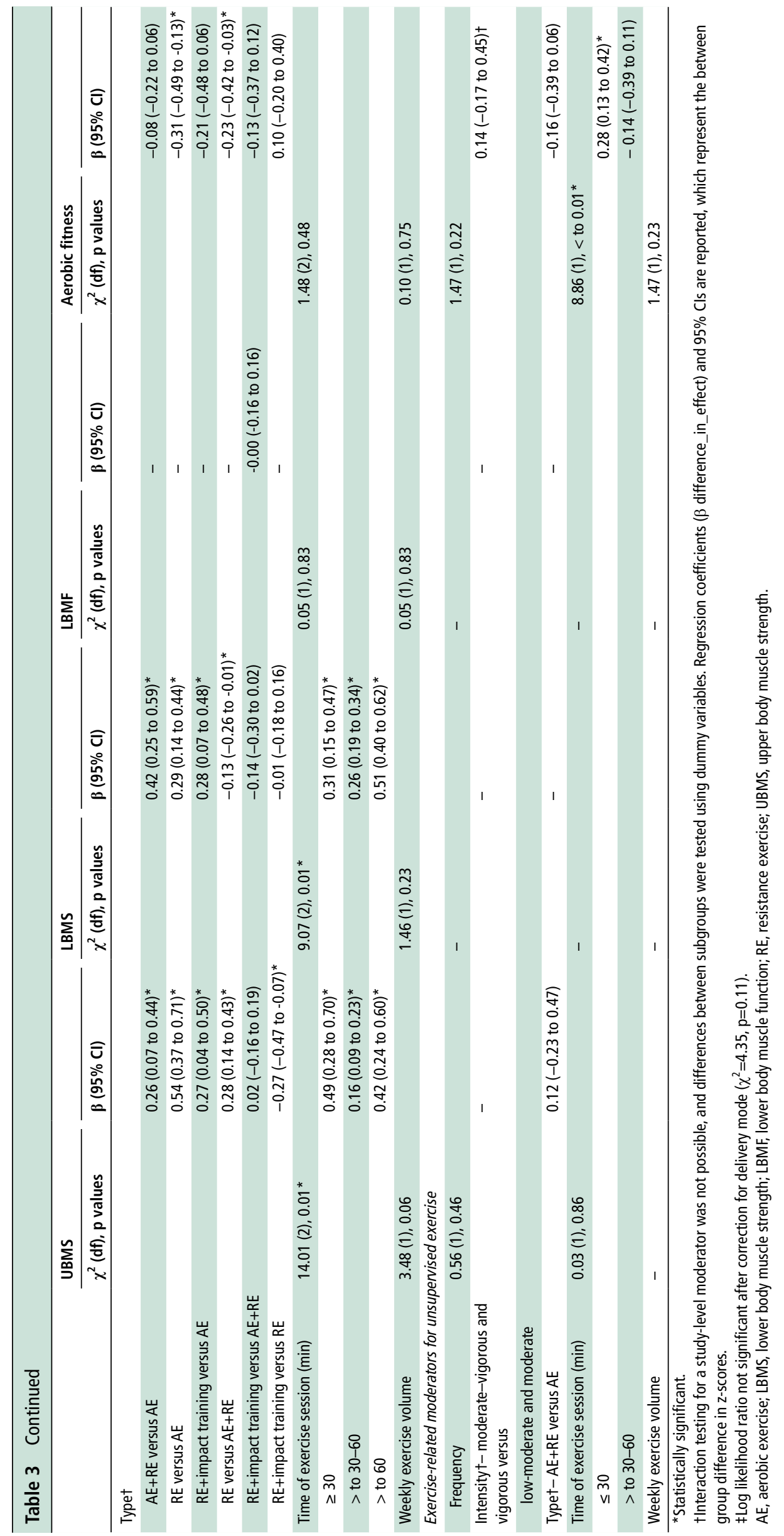


interventions (UBMS $\beta_{\text {difference in effect }}=0.19,95 \%$ CI 0.05 to 0.34 , LBMS $\beta_{\text {difference in effect }}=0.30,95 \%$ CI 0.12 to 0.48 and aerobic fitness $\beta_{\text {difference_in_effect }}=0.23,95 \%$ CI 0.12 to 0.34 ). Effects of unsupervised exercise interventions on aerobic fitness remained significant but not for UBMS and LBMS. Intervention duration moderated the effect of exercise on aerobic fitness $\left(\chi^{2}=8.47\right.$, $\mathrm{df}=1, \mathrm{p}=0.05)$. There were larger effects for an intervention duration of $\leq 12$ weeks $(\beta=0.38,95 \%$ CI 0.30 to 0.46$)$ than of $>24$ weeks $(\beta=0.14,95 \% \mathrm{CI}-0.02$ to 0.30$)$. The moderator effect of intervention duration was no longer significant after adjustment for delivery mode $\left(\chi^{2}=4.36, \mathrm{df}=1, \mathrm{p}=0.11\right)$. No other intervention-related characteristics significantly moderated the effects on UBMS, LBMS, LBMF or aerobic fitness.

\section{Exercise-related moderators for supervised exercise}

Exercise frequency significantly moderated the effects of supervised exercise interventions on UBMS $\left(\chi^{2}=17.11\right.$, $\mathrm{df}=1, \mathrm{p}<0.001)$. There were larger effects for an exercise frequency of $\geq 3$ times/week ( $\beta=0.49,95 \%$ CI 0.28 to 0.70 ) than $<3$ times/week ( $\beta=0.16,95 \%$ CI 0.11 to 0.22 ; table 3 ). There were larger effects for supervised exercise interventions including RE on UBMS and LBMS than exercise without RE (table 3). There were larger effects for supervised exercise interventions including RE on UBMS than a combination of $\mathrm{AE}+\mathrm{RE}\left(\beta_{\text {difference in effect }}=0.29,95 \%\right.$ CI 0.14 to 0.43$)$, while the effect was significantly smaller for LBMS ( $\beta_{\text {difference }}$ in effect $=-0.13,95 \% \mathrm{CI}-0.26$ to -0.01$)$. There were smaller effects for supervised exercise interventions including RE on aerobic fitness than exercise including an $\mathrm{AE}$ component (RE vs $\mathrm{AE} \beta_{\text {difference } \_ \text {in_effect }}=-0.31,95 \% \mathrm{CI}-0.49$ to -0.13 , RE vs $\mathrm{AE}+\mathrm{RE} \beta_{\text {difference _in_effect }}=-0.23,95 \% \mathrm{CI}-0.42$ to -0.03 ), except for $\mathrm{RE}+$ impact vs $\mathrm{AE}$, for which the difference in effect was not statistically significant $\left(\beta_{\text {difference in effect }}=-0.21\right.$, $95 \%$ CI -0.48 to 0.06 ). Exercise session duration moderated the effects on UBMS $\left(\chi^{2}=14.01, \mathrm{df}=2, \mathrm{p}<0.01\right)$ and LBMS $\left(\chi^{2}=9.07, \mathrm{df}=2, \mathrm{p}=0.01\right)$, with significantly larger effects for a session duration of $>60 \mathrm{~min}$ (UBMS; $\beta=0.42,95 \%$ CI 0.24 to 0.60 , and LBMS; $\beta=0.51,95 \%$ CI 0.40 to 0.62 ) than a session duration of $>30-60 \mathrm{~min}$ (UBMS; $\beta=0.16,95 \%$ CI 0.09 to 0.23 , and LBMS; $\beta=0.26$, $95 \%$ CI 0.19 to 0.34 for LBMS). Weekly exercise volume did not moderate the exercise effect for any outcome.

\section{Exercise-related moderators for unsupervised exercise}

The effects of unsupervised exercise on aerobic fitness were moderated by session duration $\left(\chi^{2}=8.86, \mathrm{df}=1, \mathrm{p}<0.01\right)$. There were larger effects for a session duration of $0-30 \mathrm{~min}$ $(\beta=0.28,95 \%$ CI 0.13 to 0.42$)$ than for a session duration of $>30-60 \mathrm{~min}(\beta=-0.14,95 \% \mathrm{CI}-0.39$ to 0.11$)$. Weekly exercise volume did not moderate the exercise intervention effect on aerobic fitness. No other exercise characteristics moderated the effects of unsupervised exercise on UBMS, LBMS, LBMF and aerobic fitness.

\section{DISCUSSION}

Based on IPD meta-analyses of 28 RCTs, there were small effects of exercise interventions on UBMS, LBMS, LBMF and aerobic fitness in patients with cancer. The effect on physical fitness was moderated by age, marital status, intervention timing, delivery mode, exercise frequency, type and time, with differences in moderator effects between the different physical fitness outcomes. Effects of exercise interventions in subgroups of patients with different demographic and clinical characteristics or studies with different intervention-related or exercise-related characteristics were small to moderate.

The beneficial effects on UBMS and LBMS correspond to the results reported in a previous systematic review ${ }^{65}$ but are smaller than reported in a previous aggregate meta-analysis. ${ }^{5}$ One explanation could be that we included more recent studies in our analysis. Another could be that the previous aggregate meta-analysis selected only high-quality RCTs based on the validity criteria from the Amsterdam-Maastricht Consensus List for Quality Assessment. Using this tool, studies with five or more internal validity characteristics were classified as highquality RCTs. In our meta-analysis, we included all studies as the Cochrane risk of bias tool used in this study does not provide a cut-off for high-quality RCTs. In addition, the effects might be influenced by the methods used to measure muscle strength, as we found statistically significant beneficial effects on $1 \mathrm{RM}$ chest press but not on grip strength. This indicates that grip strength-despite being often used as indicator of UBMS-may not be reflective of changes in UBMS as strength of the finger flexor muscles do not reflect general UBMS. The resistance training interventions of the included studies do not list specific training of these muscle groups, and absence of change is not unexpected. Finally, variation in the protocol used to measure grip strength could affect the results. ${ }^{66}$

\section{Demographic and clinical moderators}

The exercise intervention effects on LBMS were larger for patients who were unmarried or living alone than for those who were married. These results correspond to previous findings of single RCTs. ${ }^{8} 2752$ Patients who are unmarried or living alone may benefit more from supervised or guided exercise because they may have a higher adherence to the exercise programme because of less time constraints than married patients with children. ${ }^{27}$ However, being unmarried does not necessarily reflect household composition, and results were not consistent for all outcomes.

Our finding that exercise interventions were more effective in improving aerobic fitness of younger patients confirms the results reported in a single RCT. ${ }^{27}$ This could be explained by higher exercise adherence in younger patients ${ }^{6768}$ or inadequate training regimes targeting aerobic fitness in older adults. ${ }^{69}$ For example, older adults experienced larger improvements in aerobic fitness from high-intensity interval training than moderate-intensity continuous training. ${ }^{69}$ However, a systematic review investigating determinants of exercise adherence in patients with cancer reported inconsistent findings for age ${ }^{70}$ and supervised exercise interventions during and following cancer treatment can improve muscle strength and aerobic fitness in older patients with prostate or breast cancer. ${ }^{33} 387172$

\section{Intervention-related moderators}

Our finding that exercise intervention effects on UBMS were larger during than after treatment has not been reported in previous studies. The moderator effect remained significant after adjusting for intervention delivery mode and methods used to measure UBMS did not differ between studies during or following cancer treatment. Upper extremities may be particularly susceptible to a decrease in muscle strength due to physical inactivity during treatment. Thus, offering exercise intervention during treatment may be particularly important for maintaining UBMS. ${ }^{73} 74$ In contrast, daily activities, such as walking and cycling, may attenuate the decrease in LBMS, LBMF and aerobic fitness during treatment, which could 
explain why the timing of the intervention did not moderate the effect on these outcomes.

Our finding that supervised exercise interventions had larger effects on UBMS, LBMS and aerobic fitness than unsupervised exercise interventions is in line with previous IPD and aggregate meta-analyses investigating the exercise effects on self-reported QoL and self-reported physical function. ${ }^{29} 75$ The larger effects of supervised exercise may have resulted from better session attendance and guidance from a physiotherapist or exercise specialist, access to better training facilities, higher fidelity of patient exercise monitoring or better adherence to the prescribed exercise programme. ${ }^{70}$ The delivery mode did not moderate the effects on LBMF. However, this finding was based on one study, with a large CI around the effect. Furthermore, the methods used to measure LBMF may not be sensitive enough to detect change over time ${ }^{76}$ or may be vulnerable to ceiling effects. ${ }^{77}$

\section{Exercise-related moderators}

The exercise intervention effects on physical fitness were significantly moderated by different exercise FITT-factors. When aiming to improve UBMS, the ideal frequency of supervised exercise interventions appears to be at least three times per week. The significantly larger exercise effects of 0-30 min of exercise per session than $>30-60$ min per session on UBMS was unexpected and most likely resulted from the specific combinations of exercise FITT-factors rather than session duration alone. We found no moderator effect of weekly exercise volume on UBMS. This confirms the results of a single RCT in patients during chemotherapy treatment for breast cancer, ${ }^{78}$ where no difference in effect on UBMS was reported between a dose of three times $25-30 \mathrm{~min} /$ week of $\mathrm{AE}$ and three times $50-60 \mathrm{~min} /$ week of AE. However, these results should be interpreted with caution given the exercise intervention focused on $\mathrm{AE}$, which is expected to provide minimal strength adaptation. Only one study included in our analysis prescribed a session duration of $>60$ min, which was a RE-only study. ${ }^{34}$ This makes it difficult to disentangle whether differences in effect result from differences in exercise type or session duration.

There were larger beneficial effects of exercise on UBMS and LBMS of exercise interventions that included an RE component and larger beneficial effects on aerobic fitness of exercise interventions that included an AE component. This confirms previous findings from a single RCT in patients with breast cancer $^{8}$ and corresponds to the aim of the specific exercise intervention. Therefore, general training principles can be applied with patients with cancer. Most importantly, exercise prescriptions must be tailored to maximise training effects. ${ }^{79} 80$

We found that the effect of unsupervised exercise on aerobic fitness was moderated by session duration, but weekly exercise volume did not moderate the effects on aerobic fitness. Our findings for unsupervised exercise should be interpreted with caution due to the small number of studies investigating the effect of an unsupervised exercise intervention on UBMS, LBMS, LBF and aerobic fitness. The difference in effect on aerobic fitness for studies with different session duration could be explained by specific combinations of intervention-related or exercise-related characteristics.

Because FITT-factors are defined at the study level, there may be less variation in these variables, and the power to detect moderator effects is smaller than for variables at the patient level. ${ }^{81}$ To further disentangle the effects of different intervention-related or exercise-related characteristics, it is necessary to conduct second-generation studies that directly compare different exercise-related characteristics focusing on one FITT-factor while keeping others similar. ${ }^{8} 2471$

\section{Study limitations and strengths}

A limitation of this IPD meta-analysis is that the literature search was conducted in 2012, focused on QoL outcomes, and only articles published in English, German or Dutch were included. Therefore, we may not have included all recent RCTs evaluating physical fitness. ${ }^{29}$ However, we also prepared for including data from studies to be published in the years after 2012 by identifying protocol papers describing such ongoing trials and approaching the principal investigators from these studies to discuss transfer of data as soon as possible after completion of data collection. This resulted in further inclusion of data from 12 studies published up to 2017 (48\% of included studies were published between 2013 and 2017). The focus on moderators of the exercise effect on physical fitness is novel, and these results are less likely to be influenced by recent studies currently not included in the IPD meta-analysis.

There were significantly larger effects on UBMS and aerobic fitness in studies where the outcome assessor was not blinded. However, intervention characteristics differed across studies judged as being at high risk for detection bias. Therefore, we expect this influence to be minimal on our results regarding moderator effects of study level characteristics.

We did not investigate the moderator effect of combinations of anticancer treatments of the exercise effect on UBMS, LBMS, LBMF or aerobic fitness because treatment is highly correlated with cancer type. Future research should investigate the moderator effect of different anticancer treatments in more homogeneous groups of patients. Strengths of the current IPD meta-analysis are the large number of included RCTs and patients, allowing the testing of moderator effects,

What is already known?

- Previous randomised controlled trials and meta-analyses have reported beneficial effects of exercise on physical fitness in patients with cancer.

- Maintaining and improving upper and lower body muscle strength, lower body muscle function and aerobic fitness may be important during and following cancer treatment for functional independence and to improve quality of life and potentially survival.

What are the new findings?

- We found statistically significant small effects of exercise interventions on upper and lower body muscle strength, lower body muscle function and aerobic fitness in patients with cancer, with significantly higher effects on upper and lower body muscle strength and aerobic fitness for supervised exercise interventions compared with unsupervised exercise interventions.

- The effects on upper and lower body muscle strength, lower body muscle function and aerobic fitness were moderated by age, marital status, intervention timing, delivery mode, exercise frequency, type and time, with differences in moderator effects between the different physical fitness outcomes. 
using uniform analytic procedures across all RCTs. In addition, the POLARIS database is, to date, the most comprehensive IPD dataset with exercise oncology RCTs.

\section{CONCLUSION}

Exercise interventions, particularly those with a supervised component, had beneficial effects on UBMS, LBMS, LBMF and aerobic fitness in patients with cancer with different demographic and clinical characteristics, both during and following treatment. Exercise intervention effects on aerobic fitness were larger for younger patients, and the effects on LBMS were larger for patients who are unmarried or living alone. Exercise intervention effects on UBMS were larger during than after treatment and for supervised exercise with $\geq 3$ versus less sessions per week.

\section{Author affiliations}

'Department of Epidemiology \& Biostatistics, Amsterdam University Medical Center, Amsterdam Public Health Research Institute, Amsterdam, The Netherlands

${ }^{2}$ Cancer Center Amsterdam, Amsterdam, The Netherlands

${ }^{3}$ Department of Public and Occupational Health, Amsterdam Public Health Research Institute, Amsterdam University Medical Center, Amsterdam, The Netherlands

${ }^{4}$ Amsterdam School of Communication Research (ASCoR), University of Amsterdam, Amsterdam, The Netherlands

${ }^{5}$ Julius Center for Health Sciences and Primary Care, University Medical Center Utrecht, University of Utrecht, Utrecht, The Netherlands

${ }^{6}$ Division of Psychosocial Research and Epidemiology, Netherlands Cancer Institute, Amsterdam, Noord-Holland, The Netherlands

'Lane Fox Respiratory Research Unit, Guy's and St Thomas' NHS Foundation Trust, London, UK

${ }^{8}$ Institute of Psychiatric and Psychosomatic Psychotherapy, Central Institute of Mental Health, Mannheim, Germany

${ }^{9}$ Faculty of Health, University of Antwerp, Antwerp, Belgium

${ }^{10}$ Faculty of Kinesiology, Sport and Recreation, University of Alberta, Edmonton, Alberta, Canada

${ }^{11}$ School of Sport, Exercise and Health Sciences, University of Loughborough, Loughborough, UK

${ }^{12}$ Exercise Medicine Research Institute, Edith Cowan University, Joondalup, Western Australia, Australia

${ }^{13}$ Department of Respiratory Medicine, Kings College London, London, UK

${ }^{14}$ The George Washington University School of Nursing, Washington, DC, USA

${ }^{15}$ University of Twente, Enschede, The Netherlands

${ }^{16}$ School of Public Health and Social Work, Institute of Health and Biomedical Innovation, Queensland University of Technology, Brisbane, Queensland, Australia

${ }^{17}$ Fundación GIAFyS Cancer, Miranda de Ebro, Spain

${ }^{18}$ Department of Hematology, Amsterdam University Medical Center, Amsterdam, The Netherlands

${ }^{19}$ European University, Madrid, Spain

${ }^{20}$ Robertson Centre for biostatistics, Institute of Health and Wellbeing, University of Glasgow, Glasgow, UK

${ }^{21}$ Physical Activity for Health Research Center, University of Edinburgh, Edinburgh, UK

${ }^{22}$ Department of Rehabilitation, Amsterdam University Medical Center, University of Amsterdam, Amsterdam Movement Sciences, Amsterdam, The Netherlands

${ }^{23}$ Department of Medical Oncology, National Center for Tumor Diseases (NCT) and Heidelberg University Hospital, Heidelberg, Germany

${ }^{24}$ Department of Radiation Oncology, National Center for Tumor Diseases (NCT) and Heidelberg University Hospital, Heidelberg, Germany

${ }^{25}$ Division of Physical Activity, Prevention and Cancer, German Cancer Research Center (DKFZ) and National Center for Tumor Diseases (NCT), Heidelberg, Germany

${ }^{26}$ Penn State Health, College of Medicine and Cancer Institute, Hershey, Pennsylvania, USA

${ }^{27}$ Athleticum - Competence Center for Sports- and Exercise Medicine and Institute for Medical Psychology, University Medical Center Hamburg-Eppendorf, Hamburg, Germany

${ }^{28}$ Netherlands Cancer Institute, Amsterdam, The Netherlands

${ }^{29}$ Center for Quality of Life, Netherlands Cancer Institute, Amsterdam, The Netherlands

${ }^{30}$ National Advisory Unit on Late Effects after Cancer Treatment, Department of Oncology and Department of Clinical Service, Oslo University Hospital, Oslo, Norway

${ }^{31}$ Netherlands Comprehensive Cancer Organisation (IKNL), Utrecht, The Netherlands

${ }^{32}$ Johns Hopkins School of Nursing, Johns Hopkins School of Medicine, Sidney

Kimmel Comprehensive Cancer Center, Baltimore, Maryland, USA

${ }^{33}$ Knight Cancer Institute, School of Nursing, Oregon Health \& Science University, Portland, OR, USA
${ }^{34}$ College of Medicine and Cancer Institute, Penn State University, Hershey, Pennsylvania, USA

${ }^{35}$ Department of Medical Oncology, Amsterdam University Medical Center, Amsterdam, The Netherlands

Contributors MGS, TMA, LMB, JB, MJCAP and AMM contributed to the concept and design of the study. LMB and JB are members of the steering committee of POLARIS. KSC, RUN, AMM and NKA are members of the (inter)national advisory board of POLARIS. MGS and LMB, gathered, pooled and analszed the data. JKVV was involved in analysing the data. MGS, TMA and LMB drafted the manuscript. LMB, KSC, RUN, NKA, AMM, DAG, MJCAP, KS, MMS, KAG, AL, NM, AJD, AM, MB, LT, FH-R, KatHS, GA, MES, KP, GS, WHVH, RG, KarHS, KMW-S, MJV, WvM, MJK, $\mathrm{FN}$, JeW, JoW and JB are principal investigators of the randomised controlled trials of which the data are pooled for the current study and have consequently contributed to the study concept, design and conduct of the trial that they were responsible for. All authors have critically revised the manuscript and approved the final version.

Funding Via 'Bas Mulder Award' granted to LMB by the Alpe d'HuZes foundation/ Dutch Cancer Society (VU 2011-5045).

Competing interests None declared.

Provenance and peer review Not commissioned; externally peer reviewed.

\section{REFERENCES}

1 Ryan AM, Power DG, Daly L, et al. Cancer-associated malnutrition, cachexia and sarcopenia: the skeleton in the hospital closet 40 years later. Proc Nutr Soc 2016;75:199-211.

2 Jones JM, Olson $\mathrm{K}$, Catton $\mathrm{P}$, et al. Cancer-related fatigue and associated disability in post-treatment cancer survivors. J Cancer Surviv 2016;10:51-61.

3 Mishra SI, Scherer RW, Snyder C, et al. Are exercise programs effective for improving health-related quality of life among cancer survivors? A systematic review and metaanalysis. Oncol Nurs Forum 2014;41:E326-E342.

4 Jones LW, Liang Y, Pituskin EN, et al. Effect of exercise training on peak oxygen consumption in patients with cancer: a meta-analysis. Oncologist 2011;16:112-20.

5 Speck RM, Courneya KS, Mâsse LC, et al. An update of controlled physical activity trials in cancer survivors: a systematic review and meta-analysis. J Cancer Surviv 2010;4:87-100.

6 Travier N, Velthuis MJ, Steins Bisschop CN, et al. Effects of an 18-week exercise programme started early during breast cancer treatment: a randomised controlled trial. BMC Med 2015:13:121.

7 van Waart H, Stuiver MM, van Harten WH, et al. Effect of low-intensity physical activity and moderate- to high-intensity physical exercise during adjuvant chemotherapy on physical fitness, fatigue, and chemotherapy completion rates: Results of the paces randomized clinical trial. J Clin Onco/ 2015;33:1918-27.

8 Courneya KS, Segal RJ, Mackey JR, et al. Effects of aerobic and resistance exercise in breast cancer patients receiving adjuvant chemotherapy: a multicenter randomized controlled trial. J Clin Oncol 2007:25:4396-404.

9 Ohira T, Schmitz KH, Ahmed RL, et al. Effects of weight training on quality of life in recent breast cancer survivors: the Weight Training for Breast Cancer Survivors (WTBS) study. Cancer 2006;106:2076-83.

10 Caspersen CJ, Powell KE, Christenson GM. Physical activity, exercise, and physical fitness: definitions and distinctions for health-related research. Public Health Rep 1985:100:126-31.

11 Blauwhoff-Buskermolen S, Versteeg KS, de van der Schueren MA, et al. Loss of muscle mass during chemotherapy is predictive for poor survival of patients with metastatic colorectal cancer. J Clin Oncol 2016;34:1339-44.

12 Rutten IJ, van Dijk DP, Kruitwagen RF, et al. Loss of skeletal muscle during neoadjuvant chemotherapy is related to decreased survival in ovarian cancer patients. J Cachexia Sarcopenia Muscle 2016:7:458-66.

13 Vega MC, Laviano A, Pimentel GD. Sarcopenia and chemotherapy-mediated toxicity. Einstein 2016;14:580-4

14 Ostir GV, Kuo YF, Berges IM, et al. Measures of lower body function and risk of mortality over 7 years of follow-up. Am J Epidemiol 2007;166:599-605.

15 Hirvensalo M, Rantanen T, Heikkinen E. Mobility difficulties and physical activity as predictors of mortality and loss of independence in the community-living older population. J Am Geriatr Soc 2000;48:493-8.

16 Markides KS, Black SA, Ostir GV, et al. Lower body function and mortality in mexican american elderly people. J Gerontol A Bio/ Sci Med Sci 2001;56:M243-M247.

17 Peel AB, Thomas SM, Dittus K, et al. Cardiorespiratory fitness in breast cancer patients: a call for normative values. J Am Heart Assoc 2014;3:e000432.

18 Shephard RJ. Independence: a new reason for recommending regular exercise to your patients. Phys Sportsmed 2009;37:115-8.

19 Herrero F, Balmer J, San Juan AF, et al. Is cardiorespiratory fitness related to quality of life in survivors of breast cancer? J Strength Cond Res 2006;20:535-40. 
20 Casla S, López-Tarruella S, Jerez Y, et al. Supervised physical exercise improves V02max, quality of life, and health in early stage breast cancer patients: a randomized controlled trial. Breast Cancer Res Treat 2015;153:371-82.

21 Alibhai SM, Durbano S, Breunis $\mathrm{H}$, et al. A phase II exercise randomized controlled trial for patients with acute myeloid leukemia undergoing induction chemotherapy. Leuk Res 2015:1178-86.

22 Strasser B, Steindorf K, Wiskemann J, et al. Impact of resistance training in cancer survivors: a meta-analysis. Med Sci Sports Exerc 2013;45:2080-90.

23 Van Vulpen JK, Velthuis MJ, Steins Bisschop CN, et al. Effects of an Exercise Program in Colon Cancer Patients undergoing Chemotherapy. Med Sci Sports Exerc 2016:48:767-75.

24 Kampshoff CS, Chinapaw MJ, Brug J, et al. Randomized controlled trial of the effects of high intensity and low-to-moderate intensity exercise on physical fitness and fatigue in cancer survivors: results of the Resistance and Endurance exercise After ChemoTherapy (REACT) study. BMC Med 2015;13:275.

25 Buffart LM, Newton RU, Chinapaw MJ, et al. The effect, moderators, and mediators of resistance and aerobic exercise on health-related quality of life in older long-term survivors of prostate cancer. Cancer 2015;121:2821-30.

26 Kalter J, Buffart LM, Korstjens I, et al. Moderators of the effects of groupbased physical exercise on cancer survivors' quality of life. Support Care Cancer 2015;23:2623-31.

27 Courneya KS, McKenzie DC, Mackey JR, et al. Moderators of the effects of exercise training in breast cancer patients receiving chemotherapy: a randomized controlled trial. Cancer 2008;112:1845-53.

28 Buffart LM, Kalter J, Chinapaw MJ, et al. Predicting OptimaL cAncer Rehabllitation and Supportive care (POLARIS): rationale and design for meta-analyses of individual patient data of randomized controlled trials that evaluate the effect of physical activity and psychosocial interventions on health-related quality of life in cancer survivors. Syst Rev 2013;2:75

29 Buffart LM, Kalter J, Sweegers MG, et al. Effects and moderators of exercise on quality of life and physical function in patients with cancer: An individual patient data metaanalysis of 34 RCTs. Cancer Treat Rev 2017; 52:91-104.

30 Tierney JF, Vale C, Riley R, et al. Individual Participant Data (IPD) meta-analyses of randomised controlled trials: guidance on their use. PLoS Med 2015;12:e1001855.

31 Higgins JP, Altman DG, Gøtzsche PC, et al. The cochrane collaboration's tool for assessing risk of bias in randomised trials. BMJ 2011;343:d5928.

32 Galvão DA, Spry N, Denham J, et al. A multicentre year-long randomised controlled trial of exercise training targeting physical functioning in men with prostate cancer previously treated with androgen suppression and radiation from TROG 03.04 RADAR. Eur Urol 2014;65:856-64.

33 Galvão DA, Taaffe DR, Spry N, et al. Combined resistance and aerobic exercise program reverses muscle loss in men undergoing androgen suppression therapy for prostate cancer without bone metastases: a randomized controlled trial. J Clin Oncol 2010;28:340-7.

34 Speck RM, Gross CR, Hormes JM, et al. Changes in the Body Image and Relationship Scale following a one-year strength training trial for breast cancer survivors with or at risk for lymphedema. Breast Cancer Res Treat 2010;121:421-30.

35 Newton RU, Taaffe DR, Spry N, et al. A phase III clinical trial of exercise modalities on treatment side-effects in men receiving therapy for prostate cancer. BMC Cancer 2009;9:210.

36 Wall BA, GALVãO DA, Fatehee N, et al. Exercise improves v'o2max and body composition in androgen deprivation therapy-treated prostate cancer patients. Med Sci Sports Exerc 2017;49:1503-10

37 Cormie P, Galvão DA, Spry N, et al. Can supervised exercise prevent treatment toxicity in patients with prostate cancer initiating androgen-deprivation therapy: a randomised controlled trial. BJU Int 2015;115:256-66.

38 Winters-Stone KM, Dobek J, Bennett JA, et al. The effect of resistance training on muscle strength and physical function in older, postmenopausal breast cancer survivors: a randomized controlled trial. J Cancer Surviv 2012;6:189-99.

39 Winters-Stone KM, Dobek J, Nail LM, et al. Impact + resistance training improves bone health and body composition in prematurely menopausal breast cancer survivors: a randomized controlled trial. Osteoporos Int 2013;24:1637-46.

40 Winters-Stone KM, Dobek JC, Bennett JA, et al. Resistance training reduces disability in prostate cancer survivors on androgen deprivation therapy: evidence from a randomized controlled trial. Arch Phys Med Rehabil 2015;96:7-14.

41 van Waart H, Stuiver MM, van Harten WH, et al. Recruitment to and pilot results of the PACES randomized trial of physical exercise during adjuvant chemotherapy for colon cancer. Int J Colorectal Dis 2018:33.

42 Courneya KS, Mackey JR, Bell GJ, et al. Randomized controlled trial of exercise training in postmenopausal breast cancer survivors: cardiopulmonary and quality of life outcomes. J Clin Oncol 2003;21:1660-8.

43 Persoon S, ChinAPaw MJM, Buffart LM, et al. Randomized controlled trial on the effects of a supervised high intensity exercise program in patients with a hematologic malignancy treated with autologous stem cell transplantation: Results from the EXIST study. PLoS One 2017;12:e0181313.

44 Herrero F, San Juan AF, Fleck SJ, et al. Combined aerobic and resistance training in breast cancer survivors: A randomized, controlled pilot trial. Int J Sports Med 2006;27:573-80.
45 Wiskemann J, Dreger P, Schwerdtfeger R, et al. Effects of a partly self-administered exercise program before, during, and after allogeneic stem cell transplantation. Blood 2011;117:2604-13.

46 Courneya KS, Friedenreich CM, Quinney HA, et al. A randomized trial of exercise and quality of life in colorectal cancer survivors. Eur J Cancer Care 2003;12:347-57.

47 Hayes SC, Rye S, Disipio T, et al. Exercise for health: a randomized, controlled trial evaluating the impact of a pragmatic, translational exercise intervention on the quality of life, function and treatment-related side effects following breast cancer. Breast Cancer Res Treat 2013;137:175-86.

48 Daley AJ, Crank H, Saxton JM, et al. Randomized trial of exercise therapy in women treated for breast cancer. J Clin Oncol 2007;25:1713-21.

49 Steindorf K, Schmidt ME, Klassen 0, et al. Randomized, controlled trial of resistance training in breast cancer patients receiving adjuvant radiotherapy: results on cancerrelated fatigue and quality of life. Ann Oncol 2014;25:2237-43.

50 Schmidt ME, Wiskemann J, Armbrust $P$, et al. Effects of resistance exercise on fatigue and quality of life in breast cancer patients undergoing adjuvant chemotherapy: A randomized controlled trial. Int J Cancer 2015;137:471-80.

51 Wiskemann J, Schmidt ME, Klassen 0, et al. Effects of 12-week resistance training during radiotherapy in breast cancer patients. Scand J Med Sci Sports 2017;27:1500-10.

52 Courneya KS, Sellar CM, Stevinson C, et al. Randomized controlled trial of the effects of aerobic exercise on physical functioning and quality of life in lymphoma patients. $J$ Clin Oncol 2009;27:4605-12.

53 Mehnert A, Veers S, Howaldt D, et al. Effects of a physical exercise rehabilitation group program on anxiety, depression, body image, and health-related quality of life among breast cancer patients. Onkologie 2011;34:248-53.

54 Thorsen L, Skovlund E, Strømme SB, et al. Effectiveness of physical activity on cardiorespiratory fitness and health-related quality of life in young and middle-aged cancer patients shortly after chemotherapy. J Clin Oncol 2005;23:2378-88.

55 Mutrie N, Campbell AM, Whyte F, et al. Benefits of supervised group exercise programme for women being treated for early stage breast cancer: pragmatic randomised controlled trial. BMJ 2007;334:517.

56 Arbane $\mathrm{G}$, Tropman D, Jackson D, et al. Evaluation of an early exercise intervention after thoracotomy for non-small cell lung cancer (NSCLC), effects on quality of life, muscle strength and exercise tolerance: randomised controlled trial. Lung Cancer $2011 ; 71: 229-34$

57 Courneya KS, Friedenreich CM. Physical activity and cancer control. Semin Oncol Nurs 2007;23:242-52

58 American College of Sports Medicine, ACSM's Guidelines for Exercise Testing and Prescription. 9th ed: Wolters Kluwer, Lippincott Williams \& Wilkins, 2014.

59 Senn S. The many modes of meta. Drug Inf J 2000;34:535-49.

60 Durlak JA. How to select, calculate, and interpret effect sizes. J Pediatr Psychol 2009;34:917-28.

61 Cohen J. Statistical power analysis for the behavioral sciences. Orlando: Academic Press, 1977.

62 Fisher DJ, Copas AJ, Tierney JF, et al. A critical review of methods for the assessment of patient-level interactions in individual participant data meta-analysis of randomized trials, and guidance for practitioners. J Clin Epidemiol 2011;64:949-67.

63 R-Core-Team. R: A language and evironment for statistical computing, R.F.f.S. Vienna, Austria, 2016. Computing, Editor.

64 Griffith K, Wenzel J, Shang J, et al. Impact of a walking intervention on cardiorespiratory fitness, self-reported physical function, and pain in patients undergoing treatment for solid tumors. Cancer 2009;115:4874-84.

65 Stene GB, Helbostad JL, Balstad TR, et al. Effect of physical exercise on muscle mass and strength in cancer patients during treatment-a systematic review. Crit Rev Oncol Hematol 2013;88:573-93.

66 Roberts HC, Denison HJ, Martin HJ, et al. A review of the measurement of grip strength in clinical and epidemiological studies: towards a standardised approach. Age Ageing 2011;40:423-9.

67 Szymlek-Gay EA, Richards R, Egan R. Physical activity among cancer survivors: a literature review. N Z Med J 2011;124:77-89.

68 Courneya KS, Stevinson C, McNeely ML, et al. Predictors of adherence to supervised exercise in lymphoma patients participating in a randomized controlled trial. Ann Behav Med 2010:40:30-9.

69 Hwang CL, Yoo JK, Kim HK, et al. Novel all-extremity high-intensity interval training improves aerobic fitness, cardiac function and insulin resistance in healthy older adults. Exp Gerontol 2016;82:112-9.

70 Kampshoff CS, Jansen F, van Mechelen W, et al. Determinants of exercise adherence and maintenance among cancer survivors: a systematic review. Int J Behav Nutr Phys Act 2014:11:80.

71 Segal RJ, Reid RD, Courneya KS, et al. Randomized controlled trial of resistance or aerobic exercise in men receiving radiation therapy for prostate cancer. J Clin Oncol 2009;27:344-51.

72 Loh KP, Lin PJ, Uth J, et al. Exercise for managing cancer- and treatment-related side effects in older adults. J Geriatr Oncol 2018:9:405-10.

73 Atherton PJ, Greenhaff PL, Phillips SM, et al. Control of skeletal muscle atrophy in response to disuse: clinical/preclinical contentions and fallacies of evidence. Am J Physiol Endocrinol Metab 2016;311:E594-E604. 
74 Schiaffino S, Dyar KA, Ciciliot S, et al. Mechanisms regulating skeletal muscle growth and atrophy. Febs / 2013;280:4294-314.

75 Sweegers MG, Altenburg TM, Chinapaw MJ, et al. Which exercise prescriptions improve quality of life and physical function in patients with cancer during and following treatment? A systematic review and meta-analysis of randomised controlled trials. Br J Sports Med 2018:52.

76 Tomey KM, Sowers MR. Assessment of physical functioning: a conceptual model encompassing environmental factors and individual compensation strategies. Phys Ther 2009;89:705-14.

77 Frost $A E$, Langleben $D$, Oudiz $R$, et al. The 6-min walk test (6MW) as an efficacy endpoint in pulmonary arterial hypertension clinical trials: demonstration of a ceiling effect. Vascul Pharmacol 2005;43:36-9.
78 Courneya KS, McKenzie DC, Mackey JR, et al. Effects of exercise dose and type during breast cancer chemotherapy: multicenter randomized trial. J Natl Cancer Inst 2013;105:1821-32.

79 Winters-Stone KM, Neil SE, Campbell KL. Attention to principles of exercise training: a review of exercise studies for survivors of cancers other than breast. Br J Sports Med 2014:48:987-95.

80 Campbell KL, Neil SE, Winters-Stone KM. Review of exercise studies in breast cancer survivors: attention to principles of exercise training. Br I Sports Med 2012;46:909-16

81 Riley RD, Lambert PC, Abo-Zaid G. Meta-analysis of individual participant data: rationale, conduct, and reporting. BMJ 2010;340:c221. 